\title{
Enhanced far-UV reflectance of Al mirrors protected with hot-deposited $\mathrm{MgF} 2$
}

Luis Rodríguez-de Marcos, Nuria Gutiérrez-Luna, Lucía Espinosa-Yáñez, Carlos Honrado-Benítez, José ChaveroRoyán, et al.

Luis Rodríguez-de Marcos, Nuria Gutiérrez-Luna, Lucía Espinosa-Yáñez, Carlos Honrado-Benítez, José Chavero-Royán, Belén Perea-Abarca, Juan I. Larruquert, "Enhanced far-UV reflectance of Al mirrors protected with hotdeposited MgF2," Proc. SPIE 10691, Advances in Optical Thin Films VI, 106910T (5 June 2018); doi: 10.1117/12.2313635

SPIE. Event: SPIE Optical Systems Design, 2018, Frankfurt, Germany 


\title{
Enhanced Far-UV reflectance of Al mirrors protected with hot-deposited $\mathrm{MgF}_{2}$
}

\author{
Luis Rodríguez-de Marcos ${ }^{1,2,{ }^{*}, \text { Nuria Gutiérrez-Luna }}{ }^{1}$, Lucía Espinosa-Yáñez ${ }^{1}$, Carlos \\ Honrado-Benítez ${ }^{1}$, José Chavero-Royán ${ }^{1}$, Belén Perea-Abarca ${ }^{1}$, Juan I. Larruquert ${ }^{1, \dagger}$ \\ ${ }^{1}$ GOLD-IO-CSIC Instituto de Óptica-Consejo Superior de Investigaciones Científicas, \\ Madrid, Spain \\ ${ }^{2}$ Singapore Synchrotron Light Source (SSLS), National University of Singapore (NUS), \\ Singapore
}

\begin{abstract}
Mirrors based on $\mathrm{Al}$ protected with a $\mathrm{MgF}_{2}$ film provide high reflectance over a broad spectral range down to the wavelength of $120 \mathrm{~nm}$ in the Far UV (FUV). After more than 50 years since the development of this technology, a significant FUV reflectance enhancement has been obtained in the last years. Such enhancement originates mostly in the higher transparency of the $\mathrm{MgF}_{2}$ protective layer deposited on a hot Al-coated substrate.

Research has been conducted at GOLD to measure the dependence of the FUV reflectance enhancement with $\mathrm{MgF}_{2}$ deposition temperature. A reflectance enhancement was found for freshly-prepared samples; moreover, the reflectance degradation over time of $\mathrm{Al}$ films protected with hot-deposited $\mathrm{MgF}_{2}$ was also smaller than for the coatings deposited at room temperature. A reflectance as high as $90 \%$ was measured at $121.6 \mathrm{~nm}$ (hydrogen Lyman $\alpha$ line) for aged samples. A FUV reflectance enhancement was also obtained on samples fully deposited at room temperature and later annealed in vacuum. The reflectance of $\mathrm{Al}$ mirrors as a function of $\mathrm{MgF}_{2}$ deposition temperature, as well as of post-deposition annealed mirrors, and their stability over time is presented.
\end{abstract}

Structural data on film roughness, density, and main crystal orientations for mirrors with a $\mathrm{MgF}_{2}$ film deposited both at room temperature and at $250^{\circ} \mathrm{C}$ are also presented.

\section{INTRODUCTION}

Reflective coatings for the Far UV (FUV, $\lambda \in[100 \mathrm{~nm}, 200 \mathrm{~nm}]$ ) were established $\sim 60$ years ago when $\mathrm{Al}$ films protected with $\mathrm{MgF}_{2}$ were developed [1]. Al is the high-reflectance material, but Al films slightly oxidize in presence of oxygen or water vapor and this thin oxide film strongly absorbs FUV radiation. Therefore, a protection is needed for $\mathrm{Al} . \mathrm{MgF}_{2}$ and $\mathrm{LiF}$ are successful at protecting $\mathrm{Al}$ films from oxidation while keeping a high FUV reflectance due to their transparency down to $115 \mathrm{~nm}\left(\mathrm{MgF}_{2}\right)$ and $102 \mathrm{~nm}(\mathrm{LiF}) . \mathrm{MgF}_{2}$ is by far the most common protection material for $\mathrm{Al}$ because, even though $\mathrm{LiF}$ transparency extends to even shorter wavelengths; the latter material is somewhat hygroscopic, which turns more difficult to assure mirror stability. For so many years, $\mathrm{MgF}_{2}$-protected $\mathrm{Al}$ mirrors have been developed with a reflectance of $80 \%$ to $85 \%$ at the reference wavelength of $121.6 \mathrm{mn}$, the Lyman $\alpha$ spectral line of $\mathrm{H}$.

Calculations based on the transparency of VUV-grade $\mathrm{MgF}_{2}$ crystals predict a reflectance above $90 \%$ at this wavelength. This reflectance contrast between calculations and experimental values is mainly due to the imperfect growth of the $\mathrm{MgF}_{2}$ protective film. When the $\mathrm{MgF}_{2}$ film grows on a substrate at room temperature (RT), it grows more absorbing and more porous than bulk $\mathrm{MgF}_{2}$ crystals, which is a source of light scattering and causes the presence of contaminants, starting with water vapor, to fill the pores. The absorption in thin films deposited by evaporation is related with the columnar growth [2]. Both scattering

\footnotetext{
* slslvrd@nus.edu.sg ; ${ }^{\dagger}$ j.larruquert@csic.es; phone: 34- 915616800 ext 940367
} 
and absorption result in a lower reflectance of the $\mathrm{Al} / \mathrm{MgF}_{2}$ coating. $\mathrm{MgF}_{2}$ porosity can be decreased, and its FUV transparency increased, by deposition on a heated substrate [3]. Post-deposition annealing can also reduce $\mathrm{MgF}_{2}$ absorption and result in $\mathrm{Al} / \mathrm{MgF}_{2}$ coatings with increased reflectance [4]. In spite of this, no reflectance increase was observed for $\mathrm{Al} / \mathrm{MgF}_{2}$ or $\mathrm{Al} / \mathrm{LiF}$ coatings that were deposited on a heated substrate [5]; in fact, it was reported a reflectance decrease for samples deposited on substrates above $100^{\circ} \mathrm{C}$. This was due to $\mathrm{Al}$ film roughening with temperature, which destroyed the benefit of the reduced $\mathrm{MgF}_{2}$ absorption [6].

Quijada et al. [7] reported a way to overcome this situation: they deposited the Al film on the substrate at $\mathrm{RT}$, protected $\mathrm{Al}$ with an ultrathin film of $\mathrm{MgF}_{2}$, heated the sample and continued the deposition of the $\mathrm{MgF}_{2}$ film to complete the protective layer. This resulted in a significant FUV reflectance increase. The same procedure was successfully applied also to $\mathrm{Al}$ mirrors protected with $\mathrm{LiF}$ [8].

We report research to increase knowledge on $\mathrm{Al} / \mathrm{MgF}_{2}$ samples prepared with the aforementioned procedure. We have consistently prepared samples of $\mathrm{Al}$ protected with $\mathrm{MgF}_{2}$ deposited at various temperatures to obtain an optimum range for highest FUV reflectance mirrors. We also report atomic force microscopy (AFM) images, $\mathrm{x}$-ray reflectometry (XRR) and x-ray diffraction (XRD) measurements to investigate surface roughness, film density, and preferential crystal orientations in the films for samples prepared at different temperatures. Section 2 describes the main experimental equipment used in this research. Section 3 presents FUV reflectance data for fresh and aged samples, along with XRR, AFM, and XRD measurements for representative samples.

\section{EXPERIMENTAL TECHNIQUES}

Coatings were prepared in a $75-\mathrm{cm}$ diameter, $100-\mathrm{cm}$ height cylindrical deposition chamber, which was evacuated with a Velco 250A cryopump. Oil-free diaphragm plus turbomolecular pumps were used for the fore vacuum. The deposition system is placed in an ISO-6 clean room. A mild bakeout was used to accelerate degassing. Pressure in the deposition chamber was $\sim 1 \times 10^{-6} \mathrm{~Pa}$ after bakeout and $5 \times 10^{-6}$ to $10^{-5}$ $\mathrm{Pa}$ during evaporation. Tungsten thermal sources were used to evaporate both $99.999 \%$-pure $\mathrm{Al}$ and VUV-grade $\mathrm{MgF}_{2}$. Deposition rate was $\sim 6.5 \mathrm{~nm} / \mathrm{s}$ for Al films and $\sim 1.2 \mathrm{~nm} / \mathrm{s}$ for $\mathrm{MgF}_{2}$ films. Substrates were placed $70-\mathrm{cm}$ above thermal sources. Samples were heated with a resistive heater placed in contact with the back of the substrates. Temperature was measured with a thermocouple. Samples were prepared as follows. A $\sim 70-\mathrm{nm}$ thick $\mathrm{Al}$ film was deposited and it was immediately overcoated with a $\sim 4.5-\mathrm{nm}$ thick $\mathrm{MgF}_{2}$ film deposited on the unheated aluminized substrate. The sample was then heated to the desired temperature and more $\mathrm{MgF}_{2}$ was deposited on the sample to complete the protective thickness of $\sim 24 \mathrm{~nm}$ for optimum reflectance at $121.6 \mathrm{~nm}$. As soon as the sample was completed it was let to cool down back to RT. Some $\mathrm{Al} / \mathrm{MgF}_{2}$ mirrors, instead of being deposited on a hot aluminized substrate, they were deposited at RT and then post-annealed in vacuum. The annealing temperature ramp reproduced the $\mathrm{MgF}_{2}$-deposition ramp at the same temperature. Samples were nominally annealed for $12 \mathrm{~min}$.

The FUV reflectance of all samples was measured in GOLD's reflectometer. Reflectance was measured for fresh samples after a short contact to atmosphere and after some ageing period in a desiccator. The reflectometer consists in a grazing-incidence, toroidal-grating monochromator, in which the entrance and exit arms are $146^{\circ}$ apart. FUV radiation was generated in a windowless capillary discharge lamp that was fed with various pure gases or gas mixtures to generate the spectral lines to cover the spectral range of interest. Beam divergence was $\sim 1.7 \mathrm{mrad}$. FUV radiation is detected with a channel electron multiplier that was coated with a CsI-coated photocathode to extend sensitivity up to a wavelength of $200 \mathrm{mn}$. FUV reflectance was obtained by alternately measuring the reflected and the incident intensity. Reflectance measurements were performed at $5^{\circ}$ from the normal.

Diffractometry measurements were performed at Centro de Asistencia a la Investigación, Universidad Complutense de Madrid. $\theta-2 \theta$ specular reflectance measurements, which will be referred to as $\mathrm{x}$-ray reflectometry (XRR) were performed with an X'pert PRO MRD Phillips diffractometer with a parabolic $\mathrm{X}$-ray mirror in the primary beam and programmable anti-scatter and receiving slit in the secondary beam. Measurements were performed at angles from $0.15^{\circ}$ to $2.5^{\circ}$, with a step of $0.005^{\circ}$. 
Measurements to obtain the main crystal orientations, which will be referred to as $\mathrm{x}$-ray diffraction (XRD), were performed with the same diffractometer and primary-beam optics and a parallel plate collimator in the secondary beam. In grazing incidence, the angle of the primary beam is constant and small $\left(0.5^{\circ}\right)$ and we move the detector at $2 \theta$ from $20^{\circ}$ to $70^{\circ}$ angles. The source was a $\mathrm{Cu}$ anode under 45 $\mathrm{kV}$ and $40 \mathrm{~mA}$.

A high-resolution Agilent 5500 Scanning Probe Microscope was used for AFM imaging, which was used in contact mode. Vertical resolution was $\sim 0.3 \mathrm{~nm}$. Lateral resolution is given by the convolution with the 20 -nm radius tip.

\section{RESULTS AND DISCUSSION}

\subsection{FUV reflectance}

A research on the characterization of $\mathrm{Al}$ films protected with $\mathrm{MgF}_{2}$ deposited at increasing temperatures has been recently published [9]. A set of samples were prepared in which temperature was increased from RT up to $350^{\circ} \mathrm{C}$. For some samples, heating was not performed during $\mathrm{MgF}_{2}$ deposition, but after deposition was completed; the latter samples are referred to as post-annealed. Reflectance was initially measured after a short contact of the samples to the atmosphere of $\sim 1 \mathrm{~h}$, which are referred to as fresh. Fig.1 displays the FUV reflectance measured for fresh samples prepared at different deposition or postannealing temperatures. We can see that reflectance continuously increases for the $\mathrm{MgF}_{2}$ film deposited at temperatures up to $250^{\circ} \mathrm{C}$. A similar result is obtained for samples that were post-annealed up to $250^{\circ} \mathrm{C}$. However, samples with the $\mathrm{MgF}_{2}$ film deposited at $300^{\circ} \mathrm{C}$ and up (not displayed here) resulted in a significant reflectance decrease compared with the standard mirrors deposited at RT [9]. Hence, the optimum deposition temperature was found to be $\sim 250^{\circ} \mathrm{C}$. No sample was post-annealed at a temperature higher than $250^{\circ} \mathrm{C}$.
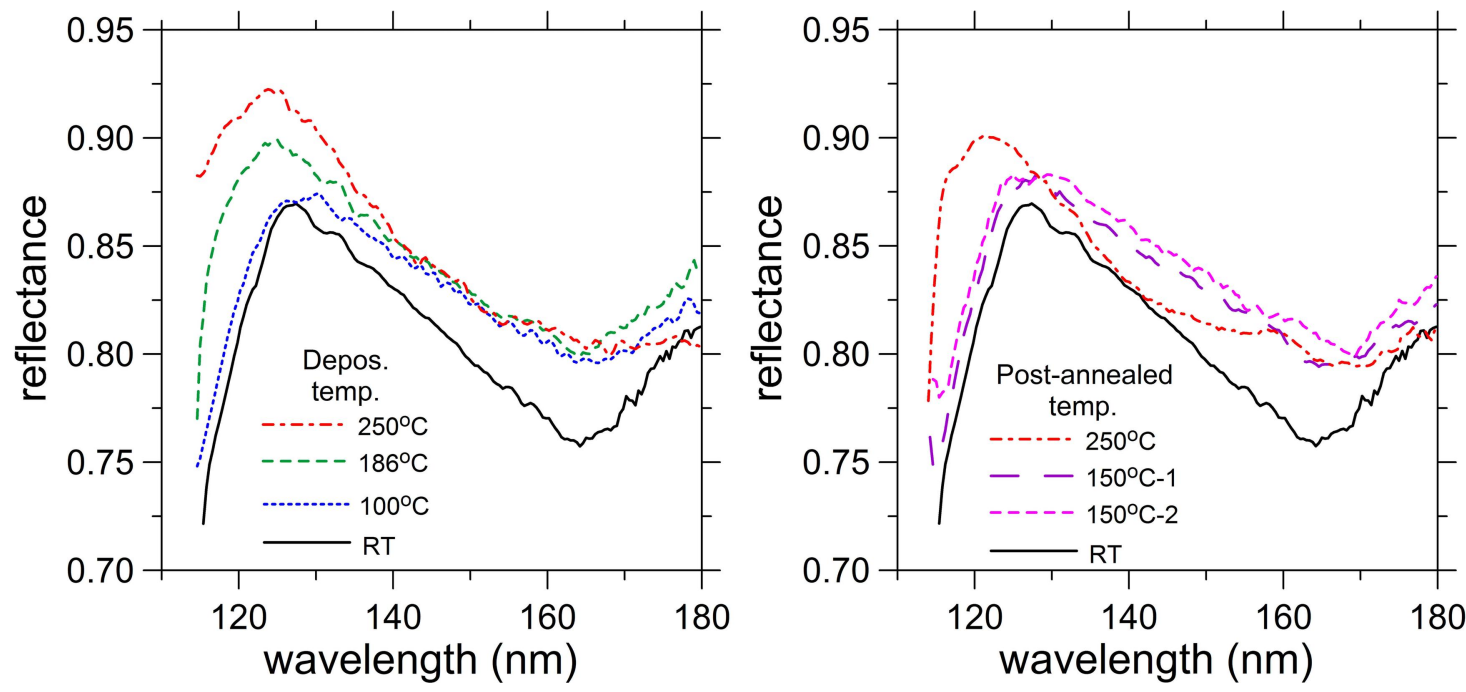

Fig. 1. Reflectance vs wavelength of fresh $\mathrm{Al} / \mathrm{MgF}_{2}$ mirrors. Left: the $\mathrm{MgF}_{2}$ film was deposited at the given temperature. Right: the $\mathrm{MgF}_{2}$ film was deposited at room temperature (RT) and the mirror was later annealed at the given temperature

Sample reflectance was measured again after a period of storage in a desiccator of 4 to 8 months. Fig. 2 displays the FUV reflectance of aged samples. The reflectance difference between the hot-deposited or post-annealed samples and the sample deposited at RT has increased upon ageing. Hence samples that involved increased temperature are more stable, which is attributed to a lower porosity of the $\mathrm{MgF}_{2}$ protective film, so that there is less room for contaminants. 

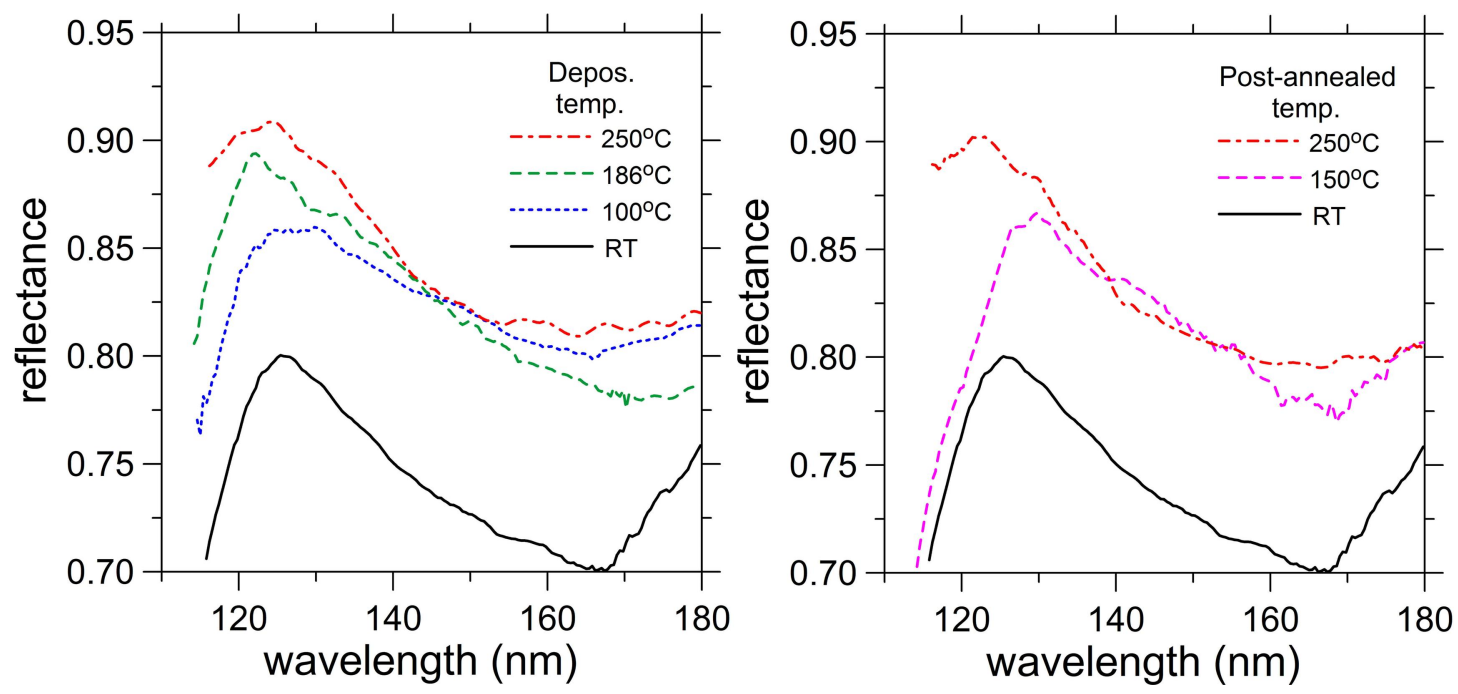

Fig. 2. Reflectance vs wavelength of aged $\mathrm{Al} / \mathrm{MgF}_{2}$ mirrors. Left: the $\mathrm{MgF}_{2}$ film was deposited at the given temperatures. Right: the $\mathrm{MgF}_{2}$ film was deposited at room temperature (RT) and the mirror was later annealed at the given temperature

A remarkable reflectance of $\sim 90 \%$ was measured at $121.6 \mathrm{~nm}$ for aged samples, both $250^{\circ} \mathrm{C}-\mathrm{MgF}_{2}$ deposited or $250^{\circ} \mathrm{C}$-post annealed, which is a value close to those given by Quijada et al. [7].
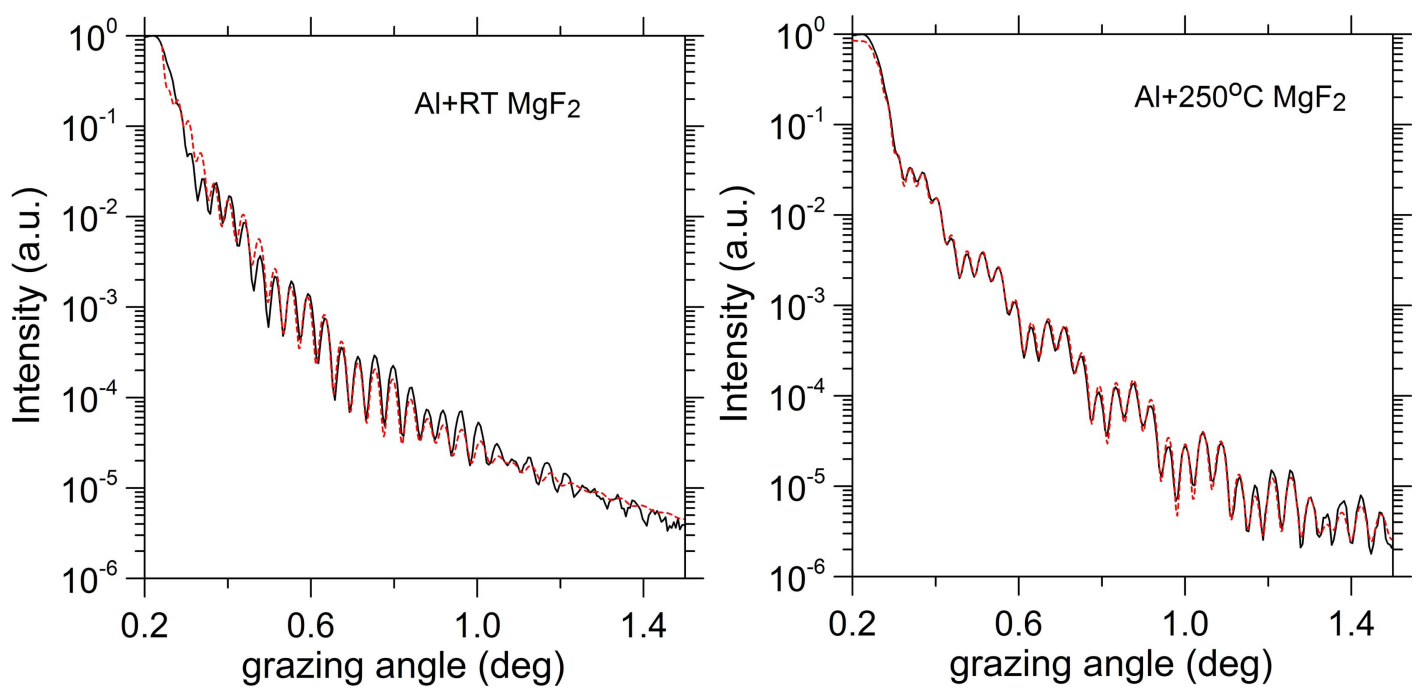

Fig. 3. DRX measurements versus grazing angle and fits for $\mathrm{Al} / \mathrm{MgF}_{2}$ mirrors. Left: $\mathrm{MgF}_{2}$ deposited at room temperature (RT). Right: $\mathrm{MgF}_{2}$ film deposited at $250^{\circ} \mathrm{C}$. Solid line: measurements. Dashed line: fit.

\subsection{Sample characterization through XRR, AFM and XRD analysis}

Samples with $\mathrm{MgF}_{2}$-deposited or post-annealed at temperatures up to $250^{\circ} \mathrm{C}$ were analysed through XRR. The $\mathrm{Cu} \mathrm{K \alpha}(\lambda=0.154 \mathrm{~nm})$ line was selected with a graphite monochromator. Fits to measurements were done between $0.2^{\circ}$ and $1.5^{\circ}$. We used IMD software [10] to fit data. Our fitting parameters were Al thickness and roughness and $\mathrm{MgF}_{2}$ density, thickness, and roughness. The density of the $\mathrm{Al}$ film was not let to vary since we assumed that metal films grow at a density close to the bulk. Fits are presented for two samples: one with the $\mathrm{MgF}_{2}$ film deposited at RT and the other at $250^{\circ} \mathrm{C}$. Fig. 3 displays XRR measurements along with the fits and Table 1 summarizes film roughness and density obtained from the 
fits. The model exhibits a good agreement with experimental data for the sample with the $\mathrm{MgF}_{2}$ film deposited at $250^{\circ} \mathrm{C}$. However, the fit for the RT sample was more imperfect. This was attributed to a gradient in the $\mathrm{MgF}_{2}$ film density, since $\mathrm{MgF}_{2}$-film porosity is expected to grow with thickness. A new model for the sample deposited at RT was attempted in which the $\mathrm{MgF}_{2}$ layer was split in two to account for a possible density gradient in thickness; however, a small density change between the split films was found, along with a negligible fit improvement. A more realistic model might fraction the layer into several sub-layers with a density that should decrease from the innermost to the outermost sub-layer.

Table 1. Film thickness, roughness and density ${ }^{\mathrm{a}}$

\begin{tabular}{|c|c|c|c|c|}
\hline Temperature & Film & Thickness $(\mathrm{nm})$ & $\sigma(\mathrm{nm})$ & $\rho\left(\mathrm{g} / \mathrm{cm}^{3}\right)$ \\
\hline \multirow{2}{*}{$\mathrm{RT}$} & $\mathrm{MgF}_{2}$ & 23.4 & 1.84 & 2.55 \\
\cline { 2 - 5 } & $\mathrm{Al}$ & 78.4 & 1.16 & 2.71 \\
\hline \multirow{2}{*}{$250^{\circ} \mathrm{C}$} & $\mathrm{MgF}_{2}$ & 23.4 & 1.19 & 3.16 \\
\cline { 2 - 5 } & $\mathrm{Al}$ & 79.0 & 0.59 & 2.71 \\
\hline
\end{tabular}

a: They were obtained from XRR fittings for samples where the $\mathrm{MgF}_{2}$ film was deposited at room temperature $(\mathrm{RT})$ or at $250^{\circ} \mathrm{C} . \sigma$ : RMS roughness

Density values were obtained from the global fitting instead of specifically from the critical angle; we found that that density of $\mathrm{MgF}_{2}$ increased with substrate temperature from $\sim 81 \%$ of bulk density $(3.16$ $\mathrm{g} / \mathrm{cm}^{-3}$ ) for the film deposited at RT to $\sim 100 \%$ of bulk density for the films deposited at $250^{\circ} \mathrm{C}$. This increase is attributed to the large porosity of the film grown at RT, and the increase in packing density due to the mobility increase of the $\mathrm{MgF}_{2}$ molecules induced by the hotter aluminized substrate. This result is compatible with those reported by Dumas et al. [2].

The above fits result in that $\mathrm{MgF}_{2}$ and $\mathrm{Al}$ films became smoother with increasing temperature, and it is particularly noticeable in $\mathrm{Al}$ films, where roughness almost halves from $\mathrm{RT}$ to $250^{\circ} \mathrm{C}$. This smoothening effect is found in samples both with $\mathrm{MgF}_{2}$ deposited on heated aluminized substrates or deposited at $\mathrm{RT}$ and post-annealed in vacuum. However, this smoothening effect on the $\mathrm{MgF}_{2}$ film was not confirmed with AFM measurements.
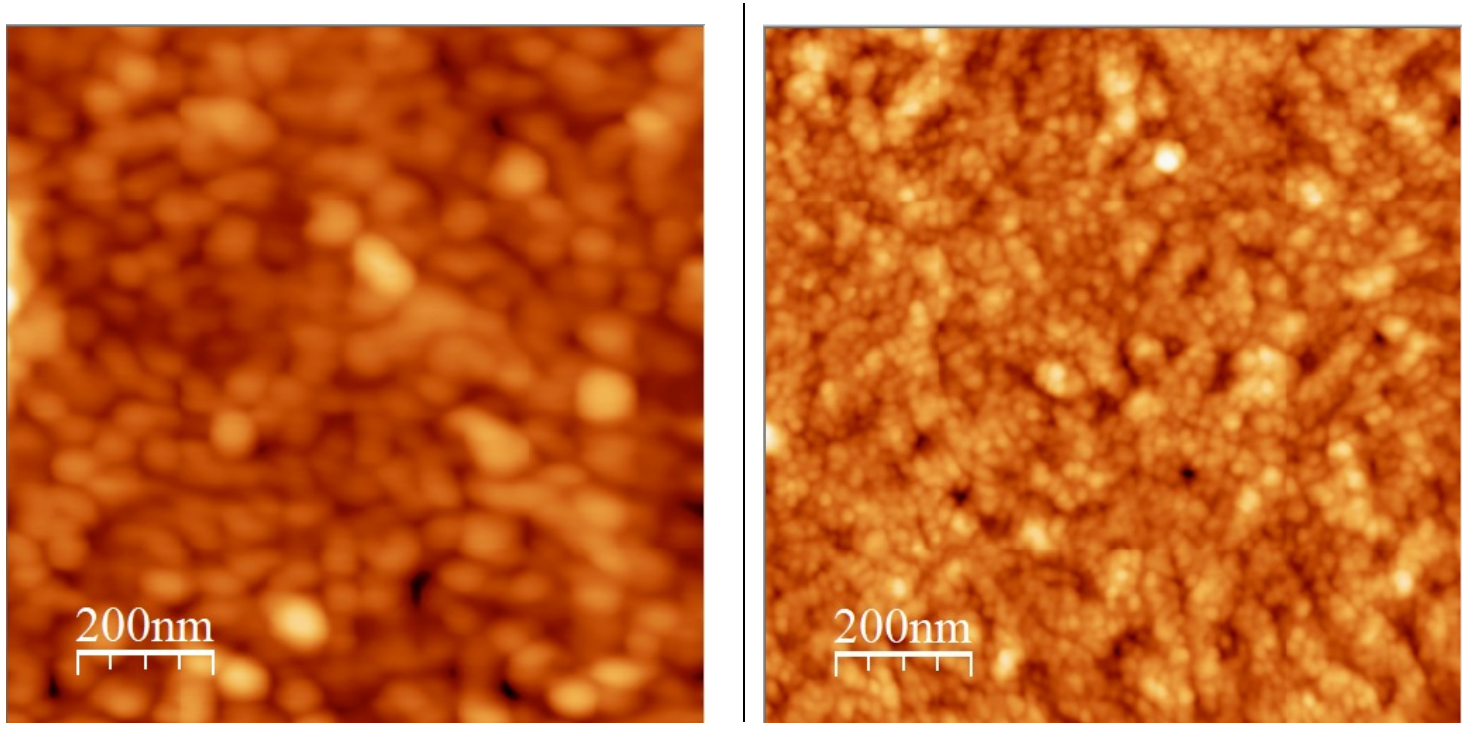

Fig. 4. Contact-mode AFM topography for RT (left) and $250^{\circ} \mathrm{C}$ (right) $\mathrm{Al} / \mathrm{MgF}_{2}$ mirrors

Two samples have been observed by AFM so far. Topography images were processed using WSxM software [11]. The following functions and algorithms for Atomic Force Microscope image processing 
were applied: flatten, plane filter, and Gaussian smooth. AFM images for RT- and $250^{\circ} \mathrm{C}$-samples are shown in Figs. 4 (2D) and 5 (3D).
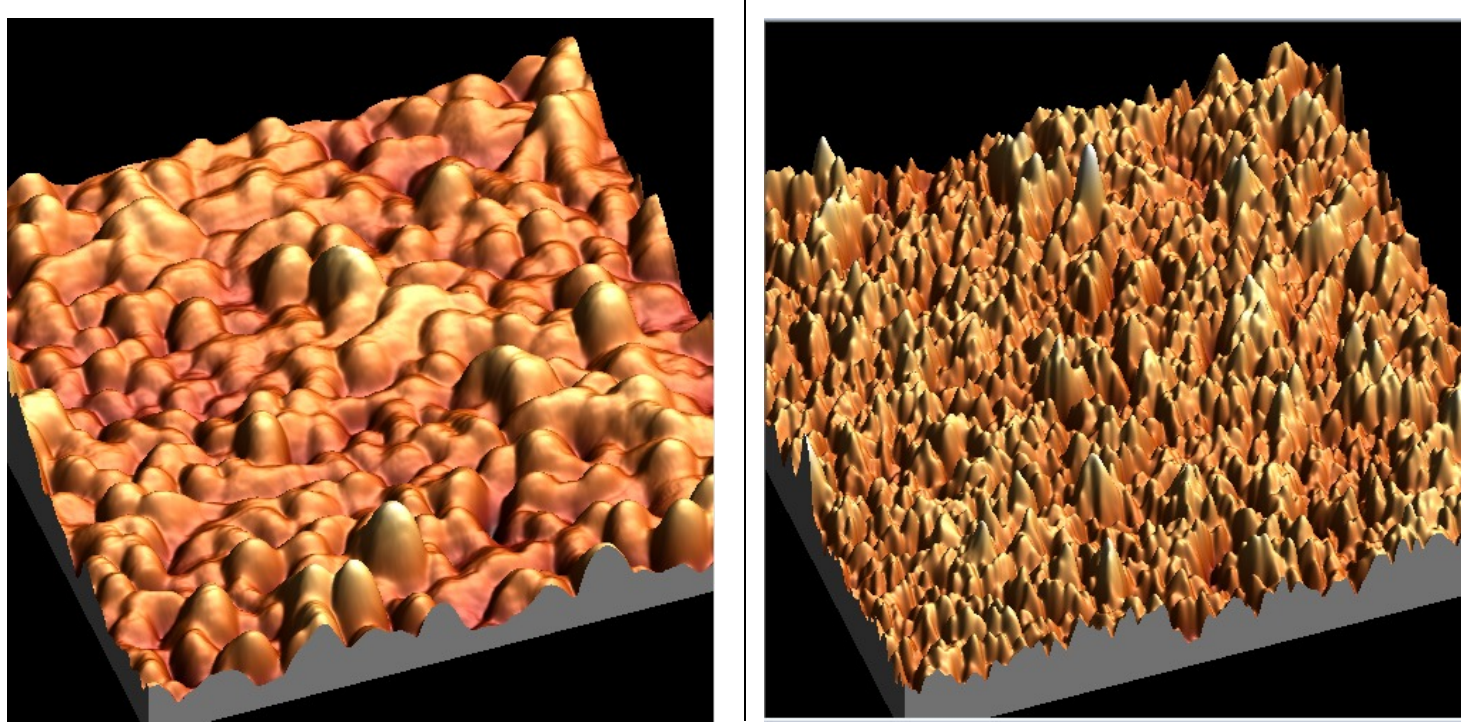

Fig. 5. 3D view of the topography of $\mathrm{RT}$ (left) and $250^{\circ} \mathrm{C}$ (right) $\mathrm{Al} / \mathrm{MgF}_{2}$ mirrors obtained with $\mathrm{AFM}$

A measurement of the average grain diameter was performed using ImageJ software with a sample of 30 grains per image. The average diameter obtained ranged between 30 and $70 \mathrm{~nm}$ for the film deposited at RT, while it was between 15 and $20 \mathrm{~nm}$ for the $250^{\circ} \mathrm{C}$ sample. There is a remarkable diameter decrease with increasing temperature, as can be easily observed in the AFM images. The $250^{\circ} \mathrm{C}$ sample presented also a more regular distribution of the grain size. The above images were also used to calculate the rootmean-square (RMS) roughness of the samples. A common value of $1.0 \mathrm{~nm}$ was obtained for the two samples.

The reduction in grain diameter looks consistent with the roughness reduction displayed in Table 1 . However, the reduction in RMS roughness with temperature obtained from XRR fits is not found in the AFM data. The two techniques measure roughness in a different way. AFM is a rather direct way to measure roughness although it only measures the topography of the outer coating interface. In XRR, roughness is involved in the proportion that each specific roughness frequency scatters the incoming $\mathrm{x}$ ray beam at grazing incidence. The roughness frequencies involved in X-ray scattering may not be the same that are obtained from AFM. The interpretation of XRR measurements also involves simplified scattering models, such as Debye-Waller factors, that are modified with the factor proposed by Nevot and Croce [12]. These differences between the two measurements techniques might explain the contrasting results. The power spectral density (PSD), i.e., the function involving the weight of each roughness frequency component, can be obtained from AFM images too. PSD is the function that contains the information to transfer roughness onto light scattering. The calculation of PSD function will also provide a better comparison of the roughness distribution on the two samples. A more complete AFM study is expected to be performed in the near future on samples involving other temperatures. 

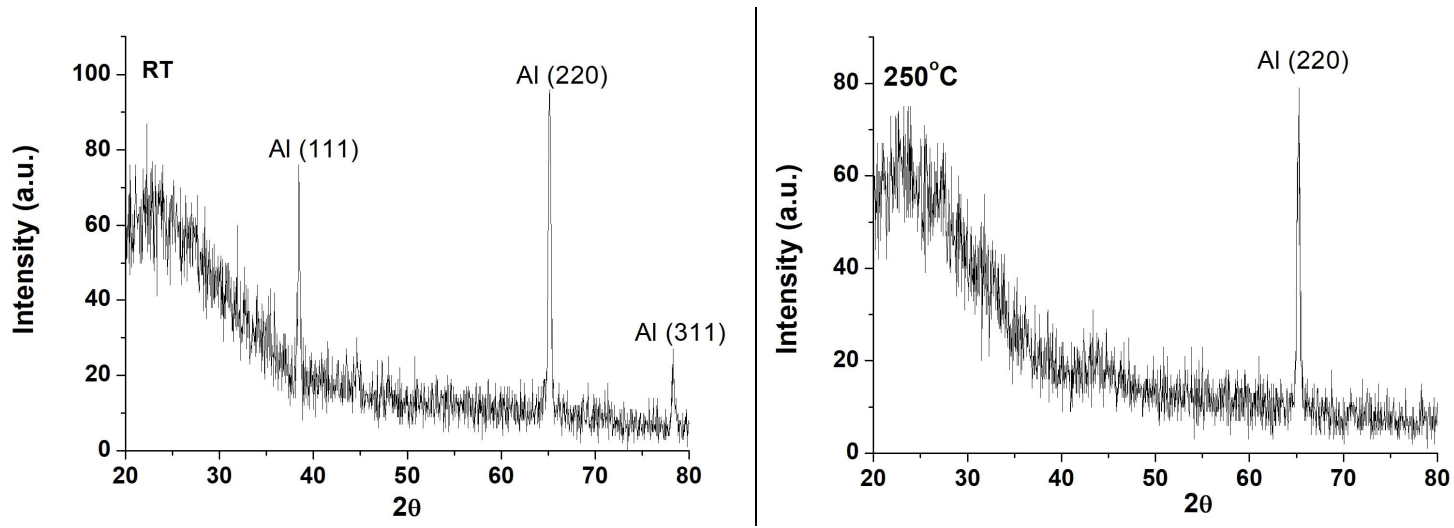

Fig. 6. DRX measurements with grazing incoming X-ray beam. Left: $\mathrm{MgF}_{2}$ deposited at room temperature (RT). Right: $\mathrm{MgF}_{2}$ film deposited at $250^{\circ} \mathrm{C}$

XRD measurements were also performed in order to find the main crystal peaks in the $\mathrm{Al} / \mathrm{MgF}_{2}$ samples deposited at different temperatures. Fig.6 displays the x-ray spectra with the identified peaks for samples with $\mathrm{MgF}_{2}$-film deposited both at $\mathrm{RT}$ and at $250^{\circ} \mathrm{C}$. Measurements were performed with the beam incoming at grazing incidence to get the largest possible contribution of the films versus the glass substrate, particularly for $\mathrm{MgF}_{2}$, which is thinner than the $\mathrm{Al}$ film. In Fig. 6, peaks displayed at $2 \theta=38.46^{\circ}$, $65.07^{\circ}$, and $78.2^{\circ}$ correspond to $\mathrm{Al}(111), \mathrm{Al}(220)$, and $\mathrm{Al}$ (311), respectively. A preferential orientation at $\mathrm{Al}(220)$ is observed in both cases. The integrated intensity of the three peaks decreases with substrate temperature increase, and the (111) and (311) orientations cannot be seen any more for the hot-deposited sample. There was a noisy oscillation close to $2 \theta=27.35^{\circ}$ which might have been identified as $\mathrm{MgF}_{2}$ (110), but it was too close to the noise level. New measurements with incremented counts are planned for these and probably for more samples to reduce the background noise and to better observe the evolution of the main crystal orientations with deposition temperature.

\section{SUMMARY AND CONCLUSIONS}

The dependence of the FUV reflectance and other parameters of $\mathrm{MgF}_{2}$-protected $\mathrm{Al}$ mirrors with respect to $\mathrm{MgF}_{2}$-film deposition temperature and of $\mathrm{Al} / \mathrm{MgF}_{2}$ deposited at $\mathrm{RT}$ and later annealed has been investigated. The optimum deposition temperature of the $\mathrm{MgF}_{2}$ film was found to be $250^{\circ} \mathrm{C}$, while a deposition temperature of $300^{\circ} \mathrm{C}$ and above resulted in a significant reflectance loss. Al films protected with a $\mathrm{MgF}_{2}$ film that was deposited at RT and later annealed displayed a similar FUV reflectance enhancement with temperature up to $250^{\circ} \mathrm{C}$. This is attributed to a smaller absorption in the $\mathrm{MgF}_{2}$ film and to a lower volume scattering in the film. The reflectance enhancement due to the increased temperature was larger for aged samples, because the reflectance of the sample deposited at RT decayed more over time, and reflectance of the samples that involved an increased temperature decreased very little.

XRR measurements were used to calculate $\mathrm{Al}$ film thickness and roughness and $\mathrm{MgF}_{2}$ film thickness, roughness, and density. $\mathrm{MgF}_{2}$ density was seen to increase from $81 \%$ of the bulk (RT) to $\sim 100 \%$ for the hot-deposited $\mathrm{MgF}_{2}$ mirror. A roughness decrease was obtained both for the $\mathrm{Al}$ and for the $\mathrm{MgF}_{2}$ film. The lower reflectance decrease over time for the coatings involving a hot temperature is attributed to the larger $\mathrm{MgF}_{2}$ density and smaller $\mathrm{MgF}_{2}$ porosity.

AFM measurements displayed a different surface structure of the sample deposited at RT compared to the sample with $\mathrm{MgF}_{2}$ film deposited at $250^{\circ} \mathrm{C}$. The average grain diameter was reduced with increasing temperature, with an average grain size of $30-70 \mathrm{~nm}$ (RT-deposited) down to $10-20 \mathrm{~nm}\left(\mathrm{MgF}_{2}\right.$-film deposited at $250^{\circ} \mathrm{C}$ ). However, the RMS roughness of the outer interface was found to be similar for the samples involving the two different temperatures. The difference between this result and the one obtained from XRR fits is attributed to the different roughness frequencies that may be involved and to the simplified roughness models used to account for interface roughness. 
DRX measurements displayed no observable presence of crystal peaks of $\mathrm{MgF}_{2}$ either deposited at RT or at $250^{\circ} \mathrm{C}$. Regarding $\mathrm{Al}$, a preferential orientation of $\mathrm{Al}(220)$ over $\mathrm{Al}(111)$ and $\mathrm{Al}(311)$ was observed for the RT sample and the intensity of the (220) peak decreased for the sample with the $\mathrm{MgF}_{2}$ deposited at $250^{\circ} \mathrm{C}$, whereas the (111) and (311) peak orientations could not be seen any more for the hot-deposited sample.

\section{ACKNOWLEDGMENTS}

We gratefully acknowledge I. Carabias and "Centro de Asistencia a la Investigación", Universidad Complutense de Madrid (UCM), for XRR and XRD measurements and for the support to take advantage of the different configurations and to fit data. We gratefully acknowledge Marisela Velez of Instituto de Catálisis y Petroleoquímica (CSIC) for her support with atomic force microscopy. This work was supported by the National Programme for Research, Subdirección General de Proyectos de Investigación, Ministerio de Ciencia e Innovación, grants AYA2013-42590-P and ESP2016-76591-P.

\section{REFERENCES}

[1] Hass G. and Tousey R., "Reflecting Coatings for the Extreme Ultraviolet," J. Opt. Soc. Am. 49, 593602 (1959).

[2] Dumas L., Quesnel E., Robic J-Y., and Pauleau Y., "Characterization of magnesium fluoride thin films deposited by direct electron beam evaporation," J. Vac. Sci. Tech. A 18, 465-468 (2000).

[3] Wood II O. R., Craighead H. G., Sweeney J. E., and Maloney P. J., "Vacuum Ultraviolet Loss in Magnesium Fluoride Films," Appl. Opt. 23, 3644-3649 (1984).

[4] Adriaens M. R. and Feuerbacher B., "Improved LiF and MgF2 Overcoated Aluminum Mirrors for Vacuum Ultraviolet Astronomy," Appl. Opt. 10, 958-959 (1971).

[5] Hutcheson Hass E. T., G., and Cox J. T., "Effect of Deposition Rate and Substrate Temperature on the Vacuum Ultraviolet Reflectance of MgF2- and LiF- Overcoated Aluminum Mirrors," Appl. Opt. 11, 2245-2248 (1972).

[6] Dymshits Y. I., Korobitsyn V. A., and Metel'nikov A. A., "Effect of Heating on the Reflectivity of Aluminum Coatings in the Vacuum Ultraviolet," Sov. J. Opt. Technol. 46, 649-651 (1979).

[7] Quijada M. A., Rice S., and Mentzell E., "Enhanced $\mathrm{MgF}_{2}$ and LiF over-coated Al mirrors for FUV space astronomy," Proc. of SPIE 8450, 84502H (2012).

[8] Quijada M. A., del Hoyo J., and Rice S., "Enhanced Far-Ultraviolet Reflectance of MgF2 and LiF Over-coated Al Mirrors," Proc. SPIE 9144, 91444G (2014).

[9] Rodríguez-de Marcos L. V., Larruquert J. I., Méndez J. A., Gutiérrez-Luna N., Espinosa-Yáñez L., Honrado-Benítez C., Chavero-Royán L., Perea-Abarca B., "Optimization of MgF2-deposition temperature for far UV Al mirrors," Opt. Express 26, 9363 (2108).

[10] Windt D. L., "IMD - Software for modeling the optical properties of multilayer films," Comput. Phys. 12, 360-370 (1998).

[11] Horcas I., Fernandez R., Gomez-Rodriguez J. M., Colchero J., Gomez-Herrero J., and Baro A. M., "WSXM: A software for scanning probe microscopy and a tool for nanotechnology," Rev. Sci. Instrum.: 78 (1), 013705 (2007).

[12] Nevot L., Croce P., "Caractérisation des surface par réflexion rasante de rayons X. Application à l'étude du polissage de quelques verres silicatés," Rev. Phys. Appl. 15, 761-779 (1980). 